\title{
Preparation and Evaluation of the Polyethylene Film Deposited With a Multilayer Graphene Membrane for Tensile Properties
}

\author{
$\mathrm{Ji} \mathrm{Li}^{1,2}$ - Jiawen Qiu ${ }^{1} \cdot$ Xiaogang Chen ${ }^{1}$ (D) $\cdot$ Muhammed Said Ergoktas ${ }^{1}$. \\ Coskun Kocabas ${ }^{1}$
}

Received: 19 May 2021 / Accepted: 20 October 2021 / Published online: 18 November 2021

(C) The Author(s) 2021

\begin{abstract}
This study aims to improve the tensile properties of the polyethylene film deposited with a multilayer graphene membrane, in order to establish the understanding of the influence of the methane to hydrogen ratio on the tensile properties of the multilayer graphene membrane. Multilayer graphene membranes were prepared using the chemical vapor deposition method. Four types of multilayer graphene membranes were prepared with different ratios of methane to hydrogen before depositing a membrane on the polyethylene film. Experiments showed that the tensile strength of the polyethylene films with multilayer graphene deposition increased 7 times and the Young's modulus 5 times more than that of pure polyethylene films, when the ratio of methane to hydrogen was set to $35 / 100 \mathrm{sccm}$. A compromise between hydrogen and methane mixture is required to achieve uniform growth of graphene. Insufficient hydrogen cannot activate the surface bound carbon that is necessary for continuous growth. Continuous and well-defined multilayer graphene was synthesized when the ratio of methane to hydrogen reached up a proper value.
\end{abstract}

Keywords Multilayer graphene membrane - Chemical vapor deposition · Ratio of methane to hydrogen $\cdot$ Tensile properties $\cdot$ Ballistic performance

\section{Introduction}

The combination of high Young's modulus (1 TPa), ultimate strength (130 GPa), and lowdensity $\left(\approx 2200 \mathrm{~kg} \cdot \mathrm{m}^{-3}\right)$ makes graphene an ideal candidate material for ballistic protection applications [1]. Lee et al. [2] designed an experiment in which microscopic projectiles were fired at multilayer graphene (MLG) sheets, giving them an accurate representation of the response of the material to similar projectiles on a macroscopic scale. The sheets

Xiaogang Chen

xiaogang_chen@hotmail.com

1 Department of Materials, University of Manchester, Manchester M13 9PL, UK

2 School of Textile Engineering, Zhongyuan University of Technology, 41 Zhongyuan Rd, Zhengzhou 450007, Henan, China 
ranged from 10 to $100 \mathrm{~nm}$ thick. The micro-bullets were accelerated to $3 \mathrm{~km} / \mathrm{s}$ by the gases produced when laser pulses were used to evaporate a gold film. The results of the testing showed that tensile stress could travel through graphene sheets at a speed of $22.2 \mathrm{~km} / \mathrm{s}$ and all the energy from the bullet was completely distributed over a large area 3 ns before the sheet was punctured. The researchers then measured the initial and final kinetic energy of the bullet in order to determine the amount of energy absorbed and dispersed by the graphene sheets. The amount of dissipated energy reached up to 0.92 megajoules of energy per kilogram of graphene, which was impressive when compared to the 0.08 megajoules per kilogram that steel exhibits. The sheets exhibited unique properties, stretching into a cone and absorbing most of the projectile's energy before breaking. This unique property is caused by the hexagonal lattice structure of graphene, consisting of tightly bound carbon atoms with strong bonds.

Although these researches were involved in nano level, they gave insight into how strong graphene could be in macroscopic applications, especially for its bullet-proofing application. Several methods have been developed to produce graphene including topdown approaches such as mechanical exfoliation and chemical exfoliation and bottom-up approaches such as epitaxial growth of graphene on SiC surfaces [3], reduction of graphene oxide [4, 5], and Chemical Vapour Deposition (CVD) [6-9]. CVD is considered the most promising method to produce large area and continuous graphene films. The most used catalysts in CVD growth of graphene are transition metals such as nickel (Ni) and copper $(\mathrm{Cu})$. CVD growth of graphene on $\mathrm{Ni}$ catalysts usually produce multilayer graphene due to Ni catalysts' high carbon solubility [10]. Despite all the efforts on graphene synthesis using CVD reactor, there is still lack of comprehensive analysis on the effect of growth parameters for fast and large-scale production of high-quality graphene.

This research aims to improve the tensile properties of the polyethylene (PE) film deposited with a multilayer graphene membrane, in order to establish the understanding of the influence of the methane to hydrogen ratio on the tensile properties of the MLG membrane, providing insight into design of a new generation of body armour system with better protection level and light weight.

\section{Experimental Methods}

In this research, large area of MLG membrane will be prepared using CVD system. Considering the cost and the feasibility of the research, the commercial polyethylene sheet is chosen to be the target substrate. The tensile strength of PE film deposited with a MLG membrane will be evaluated referring to the standard ASTM D882-18: Standard Test Method for Tensile Properties of Thin Plastic Sheeting [11].

\subsection{Preparation of Multilayer Graphene}

MLG membrane is grown on $25 \mu \mathrm{m}$ thick Nickel foil (Alfa Aesar, 12,722) substrate using CVD system which is shown in Fig. 1. As the carbon feedstock, 25 standard cubic centimetres per minute $(\mathrm{sccm})$ of $\mathrm{CH}_{4}$ gas is used at the ambient pressure during the growth. To remove the oxide layer on $\mathrm{Ni}$ substrate, the samples are annealed under a flow of $100 \mathrm{sccm}$ Argon and $100 \mathrm{sccm} \mathrm{H}_{2}$ gases at $950{ }^{\circ} \mathrm{C}$. Growth time is $5 \mathrm{~min}$, then the sample is left for fast cooling to room temperature. 


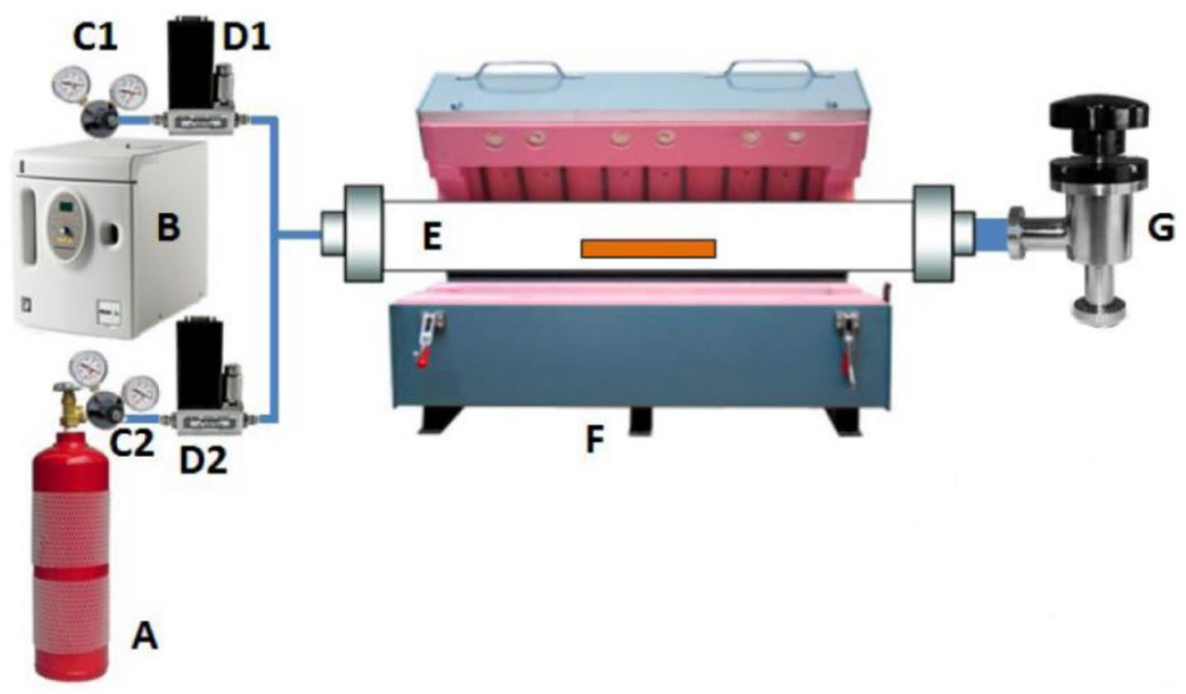

Fig. 1 Schematic of CVD system for graphene growth

A is the methane gas cylinder, providing methane precursors. B is the hydrogen generator, providing high purity hydrogen by electrolysis of water. It is safer as a gas source than conventional hydrogen gas cylinders. $\mathrm{C} 1$ and $\mathrm{C} 2$ are the gas regulators, controlling the pressure of output gases. D1 and D2 are the mass flow controllers, modulating the flow rates for different gases. $\mathrm{E}$ is the quartz tube that is the container for CVD synthesis. $\mathrm{F}$ is the horizontal split tube furnace. $\mathrm{G}$ is the angle valve, modulating the pumping rate or pressure of the system.

Transfer process of MLG membrane (size of $10 \mathrm{~cm} \times 10 \mathrm{~cm}$ ) on PE film is shown in Fig. 2. MLG membrane on Ni foil is laminated on a $20 \mu \mathrm{m}$ thick PE film that serves as a substrate for MLG during Ni foil etching. MLG membrane is detached from the nickel substrate in dense $\mathrm{FeCl}_{3}$ solution (1 Mole), then it is transferred to a deionized water container and left for $10 \mathrm{~min}$. This is repeated three times to ensure the residual $\mathrm{FeCl}_{3}$ solution is removed. Finally, the MLG membrane holding PE is blow-dried with nitrogen gas to remove the water on surface.

\subsection{Tensile Test}

PE films deposited with a MLG membrane and pure PE films are tested under tensile loading on a universal materials tester (Instron 3345 as shown in Fig. 3).

Two types of specimens are prepared to investigate the tensile properties, denoted by $\mathrm{G}_{1}$ and $G_{2} . G_{1}$ is the PE film deposited with a MLG membrane and $G_{2}$ is produced by coating MLG membrane on one side of the PE film which is then backed up by an uncoated PE film. It is referred to as a sandwich structure. In addition, one-layer pure $\mathrm{PE}\left(\mathrm{P}_{1}\right)$ and two layers pure $\mathrm{PE}\left(\mathrm{P}_{2}\right)$ are prepared under the same conditions respectively for comparison purposes.

During the tensile test, inadequate gripping force could result in severe slippage of the specimen from the clamps, and excessive gripping force could lead to specimen breakage at 


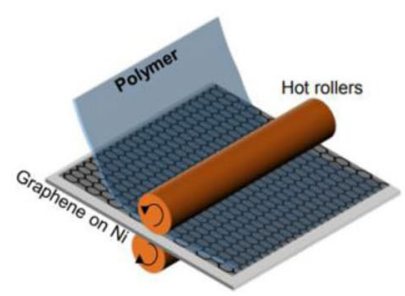

Graphene on PE

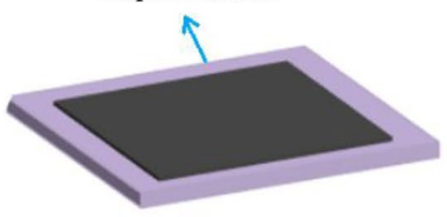

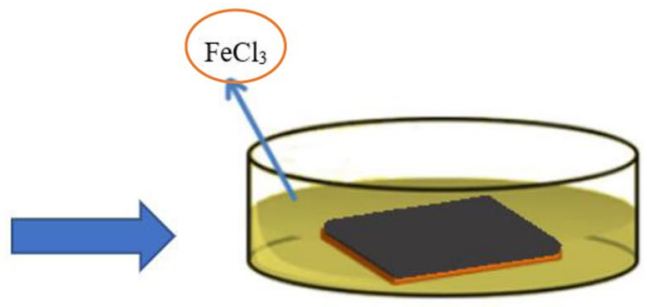

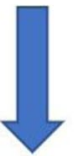

Deionized water

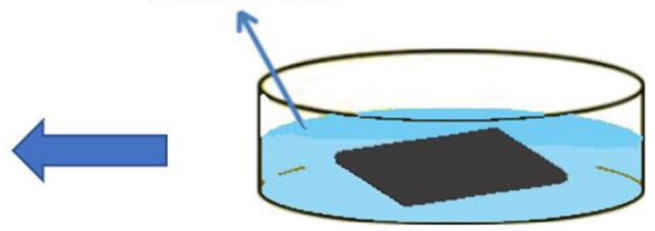

Fig. 2 Schematic of graphene transfer process from Nickle to target substrate

clamps due to stress concentration. In previous studies [12-14], non-standard specimens and replacement of rubber clamps were adopted to avoid such problems in tensile test. The photograph of the specimen tested in this study, shown in Fig. 4, indicates that the tensile test has been carried out successfully.

Fig. 3 Instron 3345

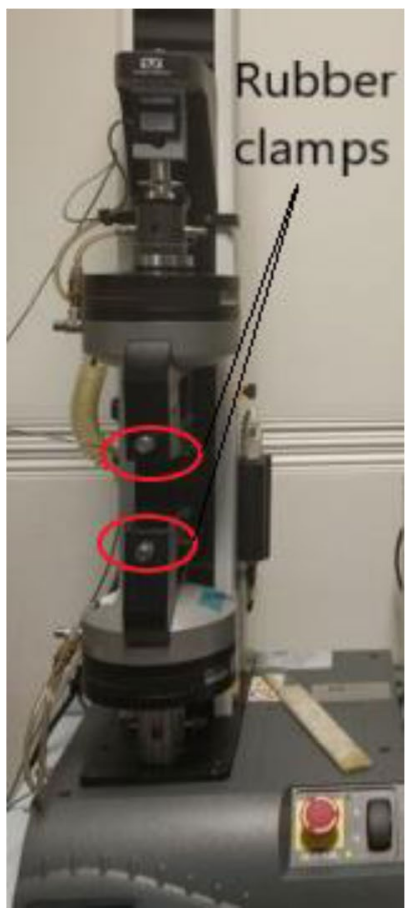


Fig. 4 Tested specimen

In this study, the specimens are cut into a rectangular shape as illustrated in Fig. 5. The gauge length and the effective width are set to $50 \mathrm{~mm}$ and $10 \mathrm{~mm}$ to ensure the effective grip. The constant tensile speed of $200 \mathrm{~mm} / \mathrm{min}$ is used. Each specimen is tested five times to determine the tensile properties. Scanning Electron Microscopy (SEM) is used for the analysis of the morphology of samples by Hitachi S3000.

\section{Results and Discussion}

According to the load and displacement of the specimen in the tensile test, the responding stress and strain on the specimen can be converted by Eqs. (1) and (2).

$$
\begin{gathered}
\sigma=\frac{F}{S} \\
\varepsilon=\frac{\Delta l}{L}
\end{gathered}
$$

where $\sigma$ is the normal stress (MPa), $F$ is the load on the specimen $(\mathrm{N}), s$ is the cross-section area of specimen $\left(\mathrm{mm}^{2}\right), \varepsilon$ is the normal strain, $\Delta l$ is the displacement $(\mathrm{mm})$, and $L$ is the length of specimen $(\mathrm{mm})$.

The tensile stress-strain curve is plotted by calculating from the average data obtained from the experiment.

Figure 6 shows that the tensile strength of sample $G_{1}$ is about twice as much as sample $P_{1}$, while the tensile strength of sample $G_{2}$ is a bit more than sample $P_{2}$ because of its 
Fig. 5 Specimens (a) $G_{1}$ and $P_{1}$ (b) $\mathrm{G}_{2}$ and $\mathrm{P}_{2}$

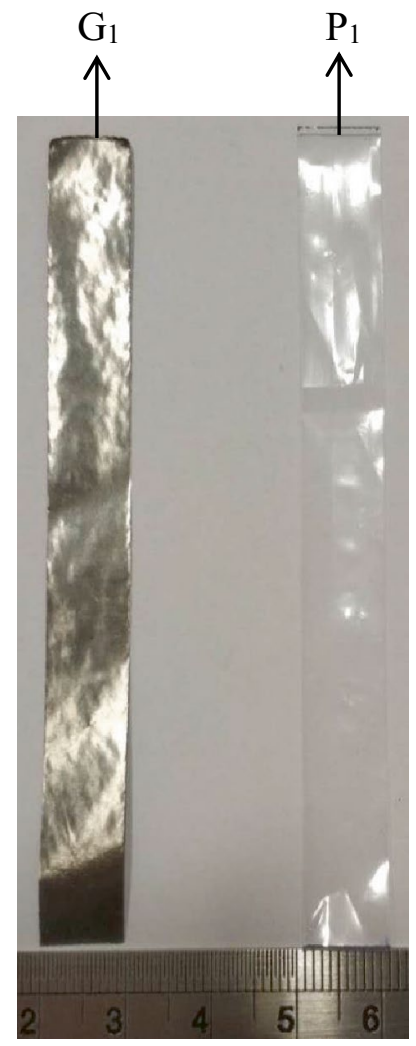

(a)

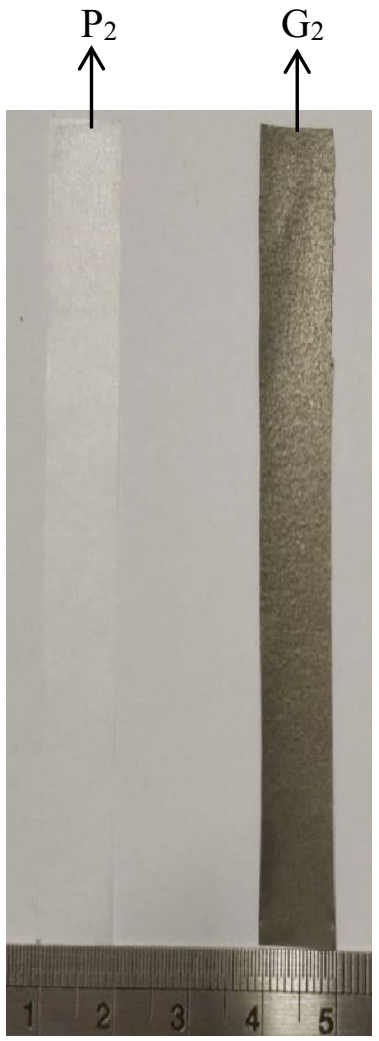

(b)

sandwich structure. $G_{1}$ has one portion of PE and one portion of MLG membrane, while $G_{2}$ has two portions of PE and one portion MLG membrane. Pristine graphene is the strongest material ever measured. However, large-area graphene films produced by means of CVD are polycrystalline and thus contain grain boundaries that can potentially weaken the material. Besides, there are many factors influencing the quality of MLG membrane, such as the growth temperature, the amount of carbon source. The transfer process can also cause ripples, holes and etchant residues which harm graphene performance. These defects could lead to structural discontinuity of the graphene membrane and hence decrease in strength.

In previous studies [15-17], continuous MLG was observed when the concentration of methane was increased gradually. In the process of preparing high quality graphene, hydrogen promotes the cracking of carbon sources and improves the uniformity and quality of graphene. In addition, hydrogen has the effect of etching graphene boundaries and internal defects, which affects the size and morphology of graphene crystals. Therefore, there is a balance between the growth and etching of graphene by hydrogen.

As explained by Vlassiouk et al. [15], the presence of hydrogen facilitates the chemisorption of methane on catalyst's surface. The possible reaction processes during the CVD growth are as below:

$$
\mathrm{CH}_{4} \rightleftharpoons \mathrm{CH}_{3}+\mathrm{H}
$$




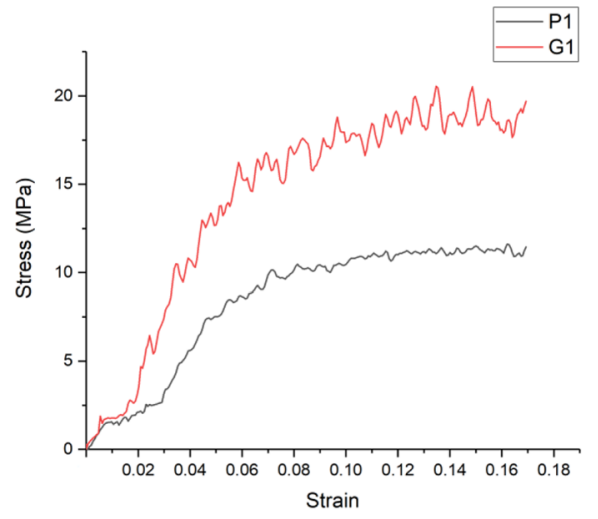

(a)

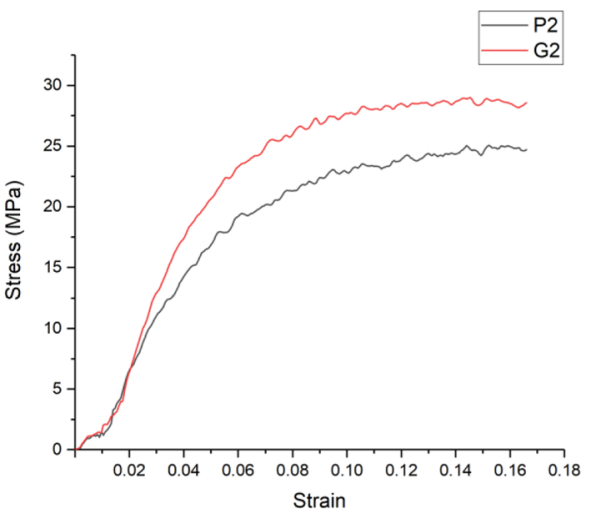

(b)

Fig. 6 Tensile stress-strain curve (a) $G_{1}$ and $P 1$ (b) $G_{2}$ and $P_{2}$

$$
\begin{gathered}
\mathrm{CH}_{3} \rightleftharpoons \mathrm{CH}_{2}+\mathrm{H} \\
\mathrm{CH}_{2} \rightleftharpoons \mathrm{CH}+\mathrm{H} \\
\mathrm{CH}_{4} \rightleftharpoons \mathrm{C}+\mathrm{H} \\
n \mathrm{C} \rightleftharpoons \text { Graphene }(\mathrm{Cn})
\end{gathered}
$$

It can be inferred that when the $\mathrm{CH}_{4} / \mathrm{H}_{2}$ is large, the reactions move towards the formation of graphene/multilayer graphene; while on the contrary, graphene formation would be hindered or etched. The methane must be chemisorbed to produce active species such as $\left(\mathrm{CH}_{3}\right)_{\mathrm{s}},\left(\mathrm{CH}_{2}\right)_{\mathrm{s}},(\mathrm{CH})_{\mathrm{s}}$ or $(\mathrm{C})_{\mathrm{s}}$. The dehydrogenation reactions without hydrogen catalysts are considered unfavourable to form $\left(\mathrm{CH}_{3}\right)_{\mathrm{s}}$ radical [15]. The existence of hydrogen atoms promotes the activation of methane physisorption and results in the formation of surface

Fig. 7 Tensile stress-strain curve

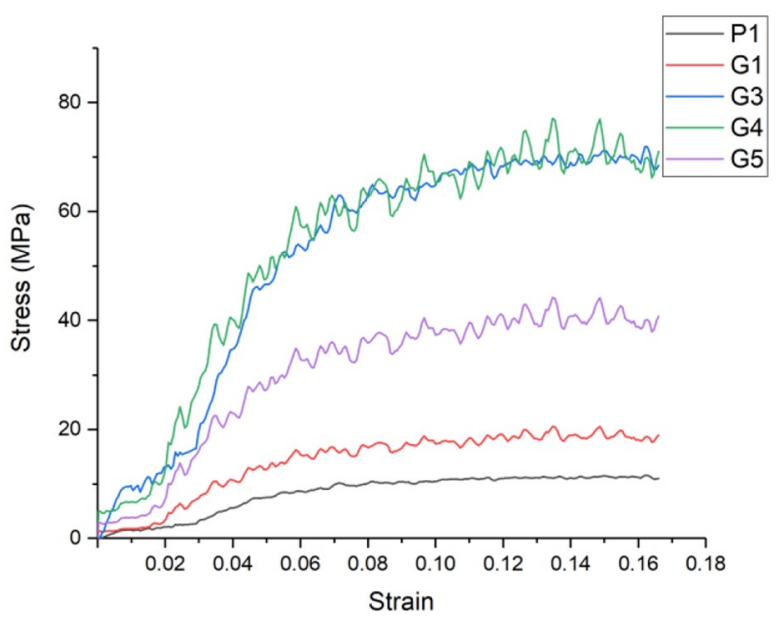


Fig. 8 Young's modulus

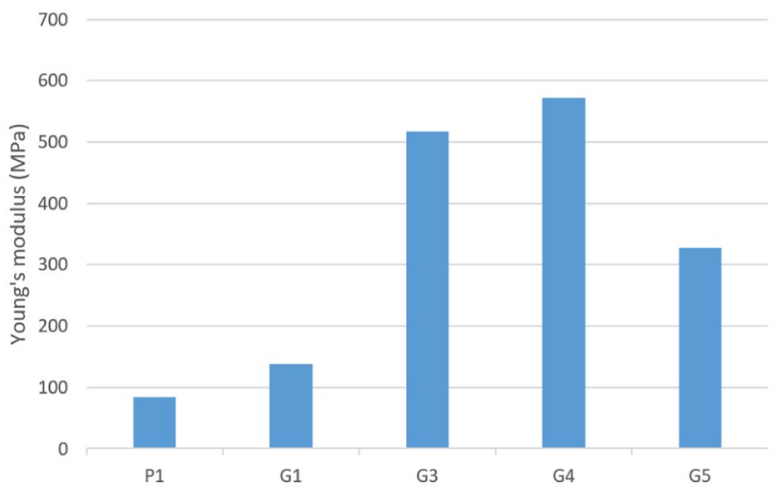

bound $\left(\mathrm{CH}_{3}\right)_{\mathrm{s}}$ radicals. Further dehydrogenation results in producing the other active surface bound which subsequently react to produce graphene.

Higher methane concentration produced graphene domain with smoother edges compared to irregular edges observed at lower methane concentration. This could be attributed to the fact that higher methane concentration would result in more hydrogen generation during the dehydrogenation process. The increase in hydrogen resulted in etching the edges of graphene domain. The etching resulted in producing fewer irregular edges and smaller domain size. A compromise between hydrogen and methane mixture is required to achieve uniform growth of graphene.

In order to further analyse the influence of the ratio of methane to hydrogen, the flow of methane is increased from 25 to $40 \mathrm{sccm}$ at the flow of $100 \mathrm{sccm}$ hydrogen and the changes in tensile properties are investigated. It has been shown in Fig. 7 and Fig. 8. The morphology of the MLG sheet is also characterized by SEM images which is showed in Fig. 9. The Raman spectrum of sample $G_{1}$ and $G_{4}$ are showed in Fig. 10 (Table 1).

Figures 7 and 8 show that the tensile stress and Young's modulus of MLG films increase gradually when the methane concentration is increased from 25 to $35 \mathrm{sccm}$ and reach to a peak when the methane concentration is $35 \mathrm{sccm}$. However, the tensile properties of the graphene-coated films come down when the methane source further increases. This is because insufficient carbon source cannot form continuous and high-quality graphene film. With the increase of the methane concentration, the proportion of hydrogen is decreased relatively, the catalyst hydrogen cannot activate sufficient surface bound carbon which is necessary for continuous growth of graphene.

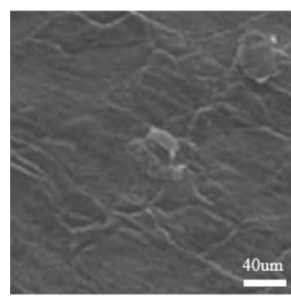

(a)

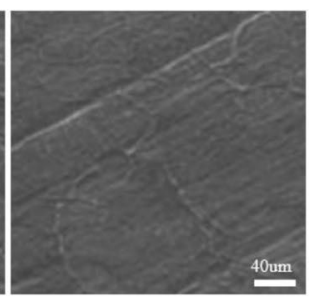

(b)

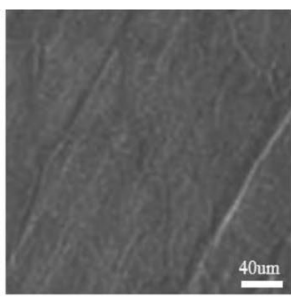

(c)

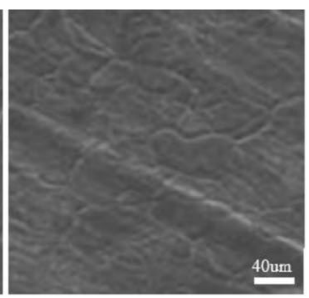

(d)

Fig. 9 SEM images of MLG films (a)sample $G_{1}$, (b)sample $G_{3}$, (c)sample $G_{4}$, (d)sample $G_{5}$ 


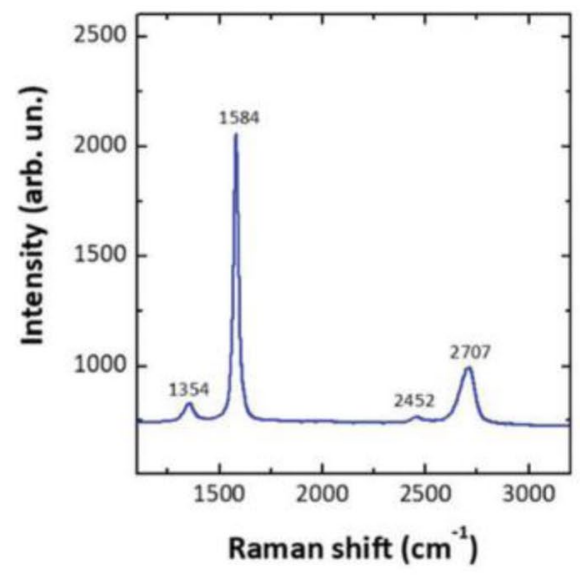

(a)

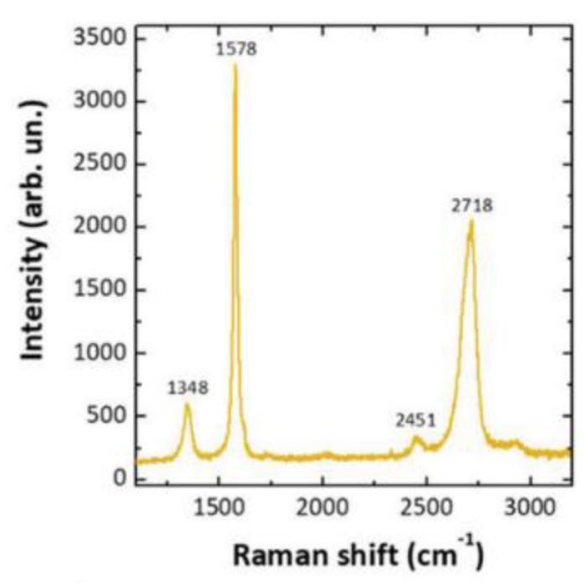

(b)

Fig. 10 Raman Spectra of the sample (a) $G_{1}$ (b) $G_{4}$

The SEM images of the top view of the graphene samples on the polyethylene substrate as shown in Fig. 9 demonstrate that $G_{3}$ and $G_{4}$ have fewer defects than $G_{1}$ and $G_{5}$. It is also observed that the surface of $\mathrm{G}_{3}$ and $\mathrm{G}_{4}$ is smoother than $\mathrm{G}_{1}$ and $\mathrm{G}_{5}$. Proper methane to hydrogen ratio is important to the growth of high-quality graphene films.

The existence of defects in graphene can be identified by the ratio of $\mathrm{D}$ band intensity $\left(\mathrm{I}_{\mathrm{D}}\right)$ to $\mathrm{G}$ band intensity $\left(\mathrm{I}_{\mathrm{G}}\right)$. Low $\mathrm{I}_{\mathrm{D}} / \mathrm{I}_{\mathrm{G}}$ intensity $<0.5$ suggests good quality graphene with less defects $[18,19]$. This intensity ratio gives a good indication of the defect level in graphene. In this case the ratio is found to be $0.4\left(\mathrm{G}_{1}\right)$ and $0.2\left(\mathrm{G}_{4}\right)$ from Fig. 10. Therefore, sample $\mathrm{G}_{4}$ has fewer defects than $\mathrm{G}_{1}$.

These tests demonstrate that the tensile strength of PE film deposited with a multilayer graphene membrane increased about 7 times and Young's modulus enhanced about 5 times than that of pure polyethylene films when the ratio of methane to hydrogen is $35 / 100 \mathrm{sccm}$, the tensile properties of multilayer graphene films have been improved by using the proper parameters, which give promise to the ballistic applications of multilayer graphene sheets. Multilayer graphene membrane can lead to lightweight, energy-absorbing material.

Table 1 Tensile stress of MLG films with different ratio of $\mathrm{CH}_{4} /$ $\mathrm{H}_{2}$

\begin{tabular}{lllll}
\hline & $\mathrm{G}_{1}$ & $\mathrm{G}_{3}$ & $\mathrm{G}_{4}$ & $\mathrm{G}_{5}$ \\
\hline $\mathrm{CH}_{4} / \mathrm{H}_{2}(\mathrm{sccm})$ & $25 / 100$ & $30 / 100$ & $35 / 100$ & $40 / 100$ \\
Annealing & Yes & Yes & Yes & Yes \\
Temperature ${ }^{\circ} \mathrm{C}$ & 950 & 950 & 950 & 950 \\
$\begin{array}{l}\text { Growth time } \\
\text { (min) }\end{array}$ & 5 & 5 & 5 & 5 \\
Pressure & Atmospheric & Atmospheric & Atmospheric & Atmospheric \\
& pressure & pressure & pressure & pressure \\
Tensile stress & 20.5 & 10.7 & 77.1 & 44.1 \\
$(\mathrm{MPa})$ & & & & \\
\hline
\end{tabular}




\section{Conclusions}

A detailed study on the preparation of PE film deposited with a MLG membrane was presented. Experiments showed that the tensile strength of the MLG on PE film was increased about 7 times and the Young's modulus enhanced 5 times compared with that of the neat PE film when the ratio of methane to hydrogen was set to $35 / 100 \mathrm{sccm}$. The effect of $\mathrm{CH}_{4} / \mathrm{H}_{2}$ was further analysed and it demonstrated that the quality of MLG membrane was dependent on the ratio of methane to hydrogen. Continuous and well-defined MLG membrane was created when the methane concentration was increased to $35 \mathrm{sccm}$. It was also identified from SEM image and Raman spectrum. With the continuous increase of the methane concentration, the proportion of hydrogen was decreased relatively, the catalyst hydrogen cannot activate sufficient surface bound carbon which is necessary for continuous growth of MLG membrane. A compromise between hydrogen and methane mixture is required to achieve uniform growth of graphene.

Acknowledgements The authors acknowledge National Graphene Institute for access to the chemical vapour deposition system. J.L. is grateful to Zhongyuan University of Technology, China for providing the scholarship during PhD study.

Data Availability The datasets generated during the current study are available from the corresponding author on reasonable request.

\section{Declarations}

Conflict of Interests The authors have no conflicts of interest to declare.

Open Access This article is licensed under a Creative Commons Attribution 4.0 International License, which permits use, sharing, adaptation, distribution and reproduction in any medium or format, as long as you give appropriate credit to the original author(s) and the source, provide a link to the Creative Commons licence, and indicate if changes were made. The images or other third party material in this article are included in the article's Creative Commons licence, unless indicated otherwise in a credit line to the material. If material is not included in the article's Creative Commons licence and your intended use is not permitted by statutory regulation or exceeds the permitted use, you will need to obtain permission directly from the copyright holder. To view a copy of this licence, visit http://creativecommons.org/licenses/by/4.0/.

\section{References}

1. Novoselov, K.S., Geim, A.K., Morozov, S.V., Jiang, D., Zhang, Y., Dubonos, S.V., et al.: Electric field effect in atomically thin carbon films. Science 306, 666 (2004)

2. Lee, J.H., Loya, P.E., Lou, J., Thomas, E.L.: Dynamic mechanical behavior of multilayer graphene via supersonic projectile penetration. Sicence 346(6213), 1092-1096 (2014)

3. Chaitoglou, S., Pascual, E., Bertran, E., Andujar, J.: Effect of a balanced concentration of hydrogen on graphene CVD growth. J. Nanomater. 2016, 54 (2016)

4. Chua, K., Pumera, M.: Chemical reduction of graphene oxide: a synthetic chemistry viewpoint. Chem. Soc. Rev. 43, 291 (2014)

5. Abdolhosseinzadeh, S., Asgharzadeh, H., Kim, H.S.: Fast and fully-scalable synthesis of reduced graphene oxide. Sci. Rep. 5, 10160 (2015)

6. Zhang, Y., Zhang, L., Zhou, C.: Review of chemical vapor deposition of graphene and related applications. Acc. Chem. Res. 46, 2329 (2013)

7. Munoz, R., Gomez-Aleixandre, C.: Review of CVD synthesis of graphene. Chem. Vap. Deposition 19, 297 (2013)

8. Chen, X., Zhang, L., Chen, S.: Large area CVD growth of graphene. Synth. Met. 210, 95 (2015) 
9. Ergoktas, S.E., Bakan, G., Steiner, P. et al.: Graphene-Enabled Adaptive Infrared Textiles, Nano Lett. 20(7), 5346-5352 (2020)

10. Huang, L., Chang, Q., Guo, G., Liu, Y., Xie, Y., Wang, T, et al.: Synthesis of high-quality graphene films on nickel foils by rapid thermal chemical vapor deposition, Carbon. 50, 511 (2012)

11. ASTM D882-18.: Standard Test Method for Tensile Properties of Thin Plastic Sheeting, ASTM International, West Conshohocken, PA, (2004)

12. Shim, V.P.W., Lim, C.T., Foo, K.J.: Dynamic mechanical properties of fabric armour. Impact Engineering 25(1), 1-15 (2001)

13. Russell, B.P., Karthikeyan, K., Deshpande, V.S., Fleck, N.A.: The high strain rate response of Ultra High Molecular-weight Polyethylene: From fibre to laminate. Int. J. Impact Eng 60, 1-9 (2013)

14. Zok, F., Fleck, N., Deshpande, V.: A Design Tool for Robust Composite Structures. The University of California, Santa Barbara: Santa Barbara, CA 93106. 22, (2010)

15. Vlassiouk, I., Regmi, M., Fulvio, P., Dai, S., Datskos, P., Eres, G., et al.: Role of hydrogen in chemical vapor deposition growth of large single-crystal graphene. ACS Nano 5, 6069 (2011)

16. Yu, Q., Jauregui, L.A., Wu, W., Colby, R., Tian, J., Su, Z., et al.: Control and characterization of individual grains and grain boundaries in graphene grown by chemical vapour deposition. Nat. Mater. 10, 443 (2011)

17. Alnuaimi, A., Almansouri, I., Saadat, I., Nayfeh, A.: Toward fast growth of large area high quality graphene using a cold-wall CVD reactor. RSC Adv. 7, 51951 (2017)

18. Malard, L., Pimenta, M., Dresselhaus, G., Dresselhaus, M.: Raman spectroscopy in graphene. Phys. Rep. 473, 51 (2009)

19. Cançado, L.G., Jorio, A., Ferreira E.H.M., Stavale, F., Achete, C.A., Capaz, R.B., Moutinho, M.V.O., Lombardo, A., Kulmala, T. S., Ferrari, A.C.: Quantifying defects in graphene via Raman spectroscopy at difffferent excitation energies, Nano Lett. 11, 3190 (2011)

Publisher's Note Springer Nature remains neutral with regard to jurisdictional claims in published maps and institutional affiliations. 